\title{
Synthesis of carbon self-doped titanium dioxide and its activity in the photocatalytic oxidation of styrene under visible light irradiation
}

\author{
Siti Hajar Alias a, b, Nurul Najidah Mohamed a, Leaw Wai Loon c, Sheela Chandren a, c,* \\ a Department of Chemistry, Faculty of Science, Universiti Teknologi Malaysia, 81310 UTM Johor Bahru, Johor, Malaysia \\ b Faculty of Applied Sciences, Universiti Teknologi MARA Perlis, 02600 Arau, Perlis, Malaysia \\ c Centre for Sustainable Nanomaterials, Ibnu Sina Institute for Scientific and Industrial Research, Universiti Teknologi Malaysia, Skudai 81310, \\ Johor, Malaysia \\ *Corresponding author: sheela@utm.my
}

\section{Article history}

Received 20 February 2019

Revised 6 March 2019

Accepted 27 March 2019

Published Online 14 April 2019

Graphical abstract

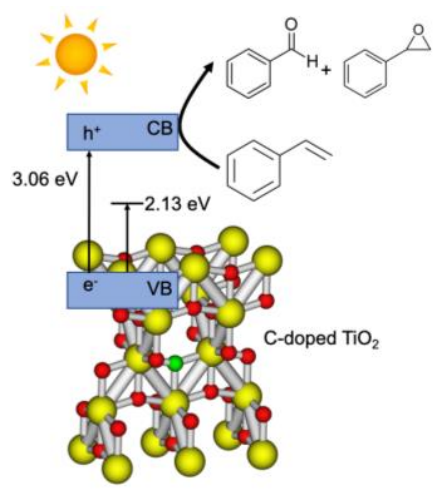

\begin{abstract}
Carbon self-doped titanium dioxide $\left(\mathrm{C} / \mathrm{TiO}_{2}\right)$ photocatalyst was synthesized by a simple sol-gel method using titanium isopropoxide as both the titanium precursor and carbon source. The effects of calcination temperatures in the range of 300 to $700{ }^{\circ} \mathrm{C}$ to the structure and physicochemical properties of the $\mathrm{C} / \mathrm{TiO}_{2}$ were investigated by X-ray diffraction (XRD), field emission scanning electron microscopy (FESEM) coupled with energy dispersive X-ray (EDX), Fourier transform infrared (FTIR) spectroscopy, UV-visible diffuse reflectance (UV-Vis DR) spectroscopy, photoluminescence spectroscopy, $\mathrm{N}_{2}$ adsorption-desorption and X-ray photoelectron spectroscopy (XPS). XPS results proved the presence of self-doped carbon at the interstitial and substitutional lattice of $\mathrm{TiO}_{2}$. The $\mathrm{C} / \mathrm{TiO}{ }_{2}$ calcined at 300 and $400{ }^{\circ} \mathrm{C}\left(\mathrm{C} / \mathrm{TiO}_{2}-300\right.$ and $\mathrm{C} / \mathrm{TiO}_{2}-400$, respectively) showed mesoporous characteristic and large surface area of about $100 \mathrm{~m}^{2} \mathrm{~g}^{-1}$. The $\mathrm{C} / \mathrm{TiO}_{2}$ photocatalysts were then tested in the photo-oxidation of styrene under visible light irradiation with aqueous hydrogen peroxide as the oxidizing agent. The $\mathrm{C} / \mathrm{TiO}_{2}$ photocatalysts were successfully activated under the irradiation of visible light, where $\mathrm{C} / \mathrm{TiO}_{2}-300$ and $\mathrm{C} / \mathrm{TiO}_{2}-400$ showed the highest total concentration of products (benzaldehyde and styrene oxide) at $1.1 \mathrm{mmol}$ and $1.0 \mathrm{mmol}$, respectively.
\end{abstract}

Keywords: Titanium dioxide, carbon doped, photocatalytic activity, styrene, photo-oxidation

\section{INTRODUCTION}

Titanium dioxide $\left(\mathrm{TiO}_{2}\right)$ is considered to be an excellent and superior photocatalytic material due to its low material cost, excellent stability, high specific surface area, environmental friendliness, nontoxicity, and superior photocatalytic activity (Ganesan et al., 2015, Lavand and Malghe, 2015). Despite its numerous advantages, two significant drawbacks have hindered the usage of $\mathrm{TiO}_{2}$ in further applications. The first drawback is that the band gap of anatase $\mathrm{TiO}_{2}$ is fairly large, at about $3.20 \mathrm{eV}$, and can only be activated under UV light irradiation in the solar spectrum. However, UV light only constitutes to a small fraction (3-5\%) of the solar spectrum (Hamal and Klabunde, 2007). In order to utilize free and abundance solar energy, more researches should be focused on visible light driven photocatalyst since visible light covers about $39 \%$ of the sunlight rays. The second drawback is the fast electron-hole pair recombination, an undesirable process where the absorbed energy is wasted as heat or reemitted without doing any chemical work. These two inherent properties are the major reasons for the low efficiency and are obstacles for practical applications of $\mathrm{TiO}_{2}$. Therefore, in order to establish an economical, safe and clean reaction system, researchers are digging into suitable methods to modify $\mathrm{TiO}_{2}$ to enhance its photocatalytic performance.
The addition of small amounts of carbon impurity to $\mathrm{TiO}_{2}$ semiconductor, or referred as $\mathrm{C}$-doped $\mathrm{TiO}_{2}$, is one of the best methods to improve the photocatalytic performance under visible light irradiation. In the past decade, C-doped $\mathrm{TiO}_{2}\left(\mathrm{C} / \mathrm{TiO}_{2}\right)$ has been synthesized by a variety of methods including thermal plasma (Park et al., 2010), xerogel carbonization (Liu et al., 2014), hydrothermal (Parayil et al., 2012) and sol-gel methods (Liu et al., 2012).

Most of the synthesis of pure $\mathrm{TiO}_{2}$ in previous studies are focused on the application in UV light, such as the photocatalytic degradation of organic pollutants under UV light irradiation. One of the simplest method in synthesizing pure $\mathrm{TiO}_{2}$ is by using titanium alkoxide as the titanium precursor. Titanium alkoxide will be hydrolyzed and the polycondensations of metal alkoxides, leading to the formation of extended network (Simonsen and Søgaard, 2010). The $\mathrm{TiO}_{2}$ formed might contain a small amount of $\mathrm{C}$ doped inside the lattice of $\mathrm{TiO}_{2}$ as a result of incomplete hydrolyzation of the titanium alkoxide. This formation of self-doped $\mathrm{C}$ could be responsible in enhancing the photocatalytic activity in the visible light region (Lettmann et al., 2001).

The photo-oxidation of styrene are of great interest at academic and commercial levels. The oxidation of styrene produces benzaldehyde, styrene oxide and phenylacetaldehyde, which are useful intermediates in the fine chemicals and pharmaceuticals industry. A few studies 
attempted to explain the formation of $\mathrm{C}$ self-doped $\mathrm{TiO}_{2}$. Park and Luna synthesized $\mathrm{C}$ self-doped $\mathrm{TiO}_{2}$ by hydrolysis of titanium butoxide, without using any external precursor and the obtained material was used in the photocatalytic reaction of 4-chlorophenol and acetominophen (Park et al., 2009, Luna et al., 2016). In another research, Gorska and coworkers (Gorska et al., 2009) reported the synthesis of $\mathrm{C}$ self-doped $\mathrm{TiO}_{2}$ by the hydrolysis of titanium (IV) isopropoxide for the degradation of phenol. However, to the best of our knowledge, research publications based on the synthesis and application of $\mathrm{C}$ self-doped $\mathrm{TiO}_{2}\left(\mathrm{C} / \mathrm{TiO}_{2}\right)$ in the photo-oxidation of styrene under the irradiation of visible light:

Therefore, in this study, the photocatalytic capability of C selfdoped $\mathrm{TiO}_{2}$ photocatalyst in visible light is shown through the photocatalytic oxidation of styrene with hydrogen peroxide $\left(\mathrm{H}_{2} \mathrm{O}_{2}\right)$ as the oxidizing agent. The presence self-doped $\mathrm{C}$ and its relation to the photocatalytic activity of $\mathrm{TiO}_{2}$ with increasing calcination temperature are investigated and studied in details.

\section{EXPERIMENTAL}

\section{Materials}

The chemicals used in the synthesis of $\mathrm{C}$ self-doped $\mathrm{TiO}_{2}$ were isopropyl alcohol (i-PrOH, 99.8\%, Qrec), ethanol (EtOH, 95\%, VChem), and titanium tetraisopropoxide (TTIP, 97\%, Sigma-Aldrich). Meanwhile, the chemicals used for the photo-oxidation reaction were styrene (99\%, Merck), acetonitrile (reagent grade, Merck), and hydrogen peroxide (30\%, Merck). As for the standard in the photooxidation of styrene, the chemicals used were benzaldehyde (99\% Aldrich) and styrene oxide (97\%, Aldrich). Commercial $\mathrm{TiO}_{2}$ was purchased from ACROS (98\%).

\section{Synthesis of $\mathrm{C}$ self-doped $\mathrm{TiO}_{2}$ photocatalyst}

$20 \mathrm{~mL}$ of ethanol and $80 \mathrm{~mL}$ of deionized water were mixed to form a mixture. $6 \mathrm{~mL}$ of titanium tetraisopropoxide (TTIP) were then added drop-wise into the mixture to form a white precipitate. The mixture was kept under constant stirring at room temperature for 24 hours. Following that, it was then centrifuged, washed and dried at $80{ }^{\circ} \mathrm{C}$ for 5 hours, to obtain $\mathrm{C} / \mathrm{TiO}_{2}$. Finally, the synthesized $\mathrm{C} / \mathrm{TiO}_{2}$ were calcined at temperatures of $300,400,500,600$ and $700{ }^{\circ} \mathrm{C}$ for 5 hours. The samples are denoted as $\mathrm{C} / \mathrm{TiO}_{2}-\mathrm{X}$, where $\mathrm{X}$ stands for the calcination temperature that was used to prepare it.

\section{Characterization}

The physicochemical properties of $\mathrm{C} / \mathrm{TiO}_{2}$ were determined by various characterization techniques. The crystalline phase and crystallite size of the $\mathrm{C} / \mathrm{TiO}_{2}$ were determined by X-ray diffractometer (Bruker AXS D8 Automatic Powder Diffractometer) operating at 40 $\mathrm{kV}, 30 \mathrm{~mA}$ and $\mathrm{Cu} \mathrm{K} \alpha$ radiation $(\lambda=1.5406 \mathrm{~nm})$ at $2 \theta=10-90^{\circ}$. The surface morphology of $\mathrm{C} / \mathrm{TiO}_{2}$ and commercial $\mathrm{TiO}_{2}$ were observed from the magnified images of the crystallites by field-emission scanning electron microscopy (FESEM). The weight percentage of atoms on the sample surface was observed by energy dispersive X-ray (EDX) analysis. The sample was scanned with parameters i.e. accelerating voltage of $15.0 \mathrm{kV}$, probe current of $2.56160 \mathrm{nA}$ and the range energy of $0-20 \mathrm{keV}$. Fourier transform infrared (FTIR) spectroscopy (Nicolet 6700 Thermo Scientific Infrared Spectrophotometer) was used to detect the existence of $\mathrm{C}$ group and other functional groups of the samples in $\mathrm{TiO}_{2}$. For the UV-visible diffuse reflectance (UV-Vis DR) spectroscopy, a Perkin Elmer Lambda 35 UV-Vis-NIR spectrometer was used. The spectra were recorded at room temperature in air at a wavelength range of 200 to $800 \mathrm{~nm}$. The photoluminescence analysis was done in order to study the electrons-holes recombination of the photocatalysts. Emission spectra of the samples were determined at room temperature using JASCO spectrofluorometer (FP-8500) with $150 \mathrm{~W}$ Xe lamp as the source of excitation. The sample excitation was conducted at $355 \mathrm{~nm}$ and the emission was scanned from 200 to $800 \mathrm{~nm}$. The specific surface area and the type of porosity of the samples were assessed from BrunauerEmmett-Teller (BET) analysis by measurement of nitrogen adsorptiondesorption (Quantachrome NOVA touch LX4) at multilevel as a function of relative pressure. The relative pressure $P / P_{0}\left(P\right.$ and $P_{0}$ are the pressure of $\mathrm{N}_{2}$ vapour and its saturation vapour pressure at $77 \mathrm{~K}$, respectively) used in the calculation of BET surface area. The data was automatically recorded into the computer. By using the model of Barrett-Joyner-Halenda (BJH), the pore volume and pore size distribution were calculated from the desorption branch. The X-ray photoelectron spectra (XPS) were recorded using high resolution multi technique X-ray spectrometer (Axis Ultra DLD XPS, Kratos). The binding energy of $\mathrm{C} 1 \mathrm{~s}$ at $285 \mathrm{eV}$ was used as the internal reference to calibrate all the binding energies. Density functional theory (DFT) by Gaussian 09 sofware was used to detect the presence of the sub-band gap energy induced by the self-doped $\mathrm{C}$ is further proved by computing the band gap energy of anatase.

\section{Photocatalytic oxidation of styrene}

The photocatalytic activity of $\mathrm{C} / \mathrm{TiO}_{2}$ photocatalysts were tested by the photo-oxidation of styrene under visible light irradiation. The reaction mixture of styrene $(10 \mathrm{mmol}), 30 \%$ aqueous $\mathrm{H}_{2} \mathrm{O}_{2}(10 \mathrm{mmol})$ as the oxidizing agent, acetonitrile $(5 \mathrm{~mL})$ as the solvent and catalyst $(50 \mathrm{mg})$, were placed in a capped-glass tube. The reactions were performed under visible light irradiation at room temperature for 24 hours. The type of lamp used as visible light source was halogen lamp with the power of $150 \mathrm{~W}$. The reactions were placed at a distance of 10 $\mathrm{cm}$ from the light source and magnetically stirred throughout the irradiation. The blank reaction was also carried out in same condition but without catalyst. After 24 hours, the catalyst and products were separated from the mixture by centrifugation.

Gas chromatography-flame ionization detector (GC-FID) (Shimadzu GC-2014) with non-polar capillary column (BPX5) was used to identify the reaction product of styrene oxidation. A column flow of $3 \mathrm{~mL} / \mathrm{min}$ with nitrogen and hydrogen as carrier gas were used. Operating conditions of GC-FID were as follows: oven temperature of $80{ }^{\circ} \mathrm{C}$; initial temperature of $80{ }^{\circ} \mathrm{C}$; initial time of $1 \mathrm{~min}$; final temperature of $140{ }^{\circ} \mathrm{C}$; hold time of $0.5 \mathrm{~min}$; rate of $15{ }^{\circ} \mathrm{C} \mathrm{min}{ }^{-1}$. Standards of products (benzaldehyde and styrene oxide) were prepared with acetonitrile as the solvent in order to obtain the calibration curve and allow the identification of products. The concentration of products (mmol) was calculated using the equation obtained from the calibration curve graph.

\section{RESULTS AND DISCUSSION}

\section{Physicochemical properties of $\mathrm{C} / \mathrm{TiO}_{2}$ at different calcination temperatures}

The presence of the self-doped carbon in the $\mathrm{TiO}_{2}$ lattice has been proven by the analyses of EDX, FTIR and XPS. Table 1 shows the elemental composition of $\mathrm{C} / \mathrm{TiO}_{2}$ determined by EDX. The results confirmed the presence of $\mathrm{Ti}, \mathrm{O}$ and $\mathrm{C}$ as the main elements in $\mathrm{C} / \mathrm{TiO}_{2}$. As compared to commercial $\mathrm{TiO}_{2}$, the carbon composition for $\mathrm{C} / \mathrm{TiO}_{2}$ shows higher amount of self-doped carbon incorporated into $\mathrm{TiO}_{2}$ lattice. With the increase of calcination temperature, the amount of carbon in $\mathrm{C} / \mathrm{TiO}_{2}$ were decreased as carbon was decomposed during the calcination process.

Fig. 1 shows the FTIR spectra for $\mathrm{C} / \mathrm{TiO}_{2}$ photocatalyts at calcination temperatures of $300,400,500,600$, and $700{ }^{\circ} \mathrm{C}$. For $\mathrm{C} / \mathrm{TiO}_{2}$, a weak adsorption peak observed in $\mathrm{C} / \mathrm{TiO}_{2}$ at the wavelength of 1664 1707 and $1260-1000 \mathrm{~cm}^{-1}$, which are attributed to the stretching vibrations of $\mathrm{C}=\mathrm{O}$ and $\mathrm{C}-\mathrm{O}$, respectively. The observation of these peaks further proved the presence of self-doped carbon into $\mathrm{TiO}_{2}$ lattice of $\mathrm{C} / \mathrm{TiO}_{2}$. A broad adsorption peak at $3000-3500 \mathrm{~cm}^{-1}$ and the adsorption peak at $1630 \mathrm{~cm}^{-1}$ in both $\mathrm{C} / \mathrm{TiO}_{2}$ and commercial $\mathrm{TiO}_{2}$ were assigned to the surface hydroxyl groups (Kumar et al., 2000). It was observed that when the calcination increased to high temperature, these hydroxyl peaks were decreased and reduced significantly. In addition, the broad peak observed at around $450-890 \mathrm{~cm}^{-1}$ corresponded to the $\mathrm{Ti}-\mathrm{O}$ bond.

XPS measurements were carried out to determine the concentrations of carbon and their chemical states. The XPS survey spectra in Fig. 2 (a) confirmed the existence of Ti, $\mathrm{O}$ and $\mathrm{C}$ elements in $\mathrm{C} / \mathrm{TiO}_{2}$ and the atomic concentration of the elements are tabulated in Table 1. The atomic percentage of carbon element decreased with increasing calcination temperature. 
Table 1 Summary of the physicochemical properties of the commercial $\mathrm{TiO}_{2}$ and synthesized $\mathrm{C} / \mathrm{TiO}_{2}$.

\begin{tabular}{|c|c|c|c|c|c|c|c|c|c|c|c|}
\hline \multirow[t]{2}{*}{ Samples } & \multirow{2}{*}{$\begin{array}{l}\text { Crystallite } \\
\text { Size }(\mathrm{nm})^{\mathrm{a}}\end{array}$} & \multicolumn{3}{|c|}{ Atomic Weight ${ }^{\mathrm{b}}(\%)$} & \multicolumn{3}{|c|}{$\begin{array}{c}\text { Atomic } \\
\text { Concentration }{ }^{\mathrm{c}}(\%)\end{array}$} & \multirow{2}{*}{$\begin{array}{l}\text { Band } \\
\text { Gap }^{d} \\
(e V)\end{array}$} & \multirow{2}{*}{$\begin{array}{c}\text { Surface } \\
\text { Area }^{\mathrm{e}} \\
\left(\mathrm{m}^{2} / \mathrm{g}\right)\end{array}$} & \multirow{2}{*}{$\begin{array}{c}\text { Pore } \\
\text { Volume } \\
\left(\mathrm{cm}^{3} / \mathrm{g}\right)\end{array}$} & \multirow{2}{*}{$\begin{array}{c}\text { Pore } \\
\text { Diameter } \\
(\mathrm{nm})\end{array}$} \\
\hline & & $\mathrm{Ti}$ & 0 & C & $\mathrm{Ti}$ & 0 & $\mathrm{C}$ & & & & \\
\hline Commercial & 26.26 & 55.5 & 39.6 & 4.9 & 21 & 47 & 32 & 3.44 & 11 & $\mathrm{~N} / \mathrm{A}$ & $\mathrm{N} / \mathrm{A}$ \\
\hline $\mathrm{C} / \mathrm{TiO}_{2}-300$ & 5.52 & 51.3 & 40.6 & 8.1 & - & - & - & 3.54 & 150 & 0.32 & 4.6 \\
\hline $\mathrm{C} / \mathrm{TiO}_{2}-400$ & 6.99 & - & - & - & - & - & - & 3.56 & 116 & 0.28 & 5.4 \\
\hline $\mathrm{C} / \mathrm{TiO}_{2}-500$ & 12.11 & - & - & - & 21 & 49 & 30 & 3.49 & 64 & 0.14 & 6.3 \\
\hline $\mathrm{C} / \mathrm{TiO}_{2}-600$ & 28.20 & - & - & - & - & - & - & 3.21 & 12 & 0.03 & 8.1 \\
\hline $\mathrm{C} / \mathrm{TiO}_{2}-700$ & 28.75 & 57.2 & 35.0 & 7.7 & 29 & 53 & 18 & 3.13 & 7 & $\mathrm{~N} / \mathrm{A}$ & $\mathrm{N} / \mathrm{A}$ \\
\hline
\end{tabular}

${ }^{a}$ Calculated by Scherrer equation. ${ }^{b}$ Detemined from the EDX analysis. ${ }^{c}$ Calculated from XPS spectra. ${ }^{d}$ Optical band edge from Tauc plot of UV absorption studies. ${ }^{e}$ BET surface area calculated from the linear part of the BET plot. ${ }^{\dagger}$ Calculated from BJH distribution

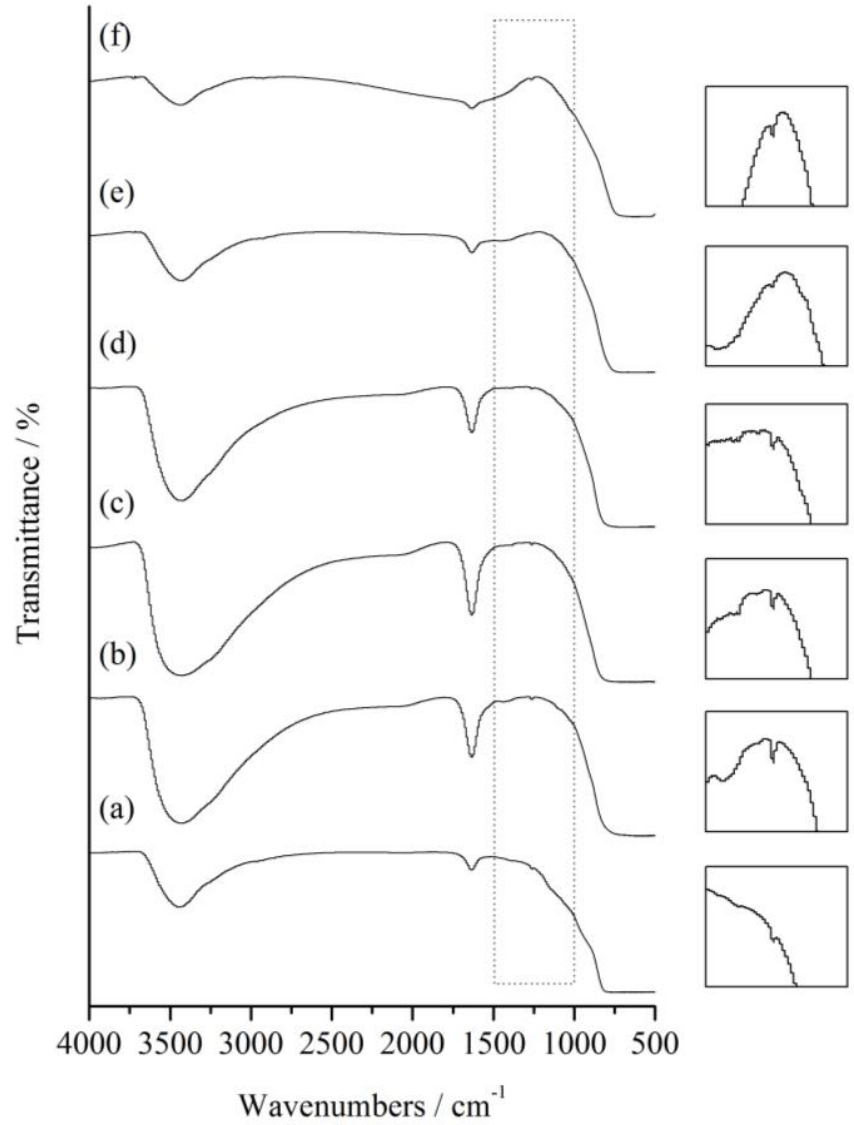

Fig. 1 FTIR spectra of (a) commercial $\mathrm{TiO}_{2}$ and $\mathrm{C} / \mathrm{TiO}{ }_{2}$ samples at different calcination temperatures of (b) 300 , (c) 400, (d) 500, (e) 600 and (f) $700{ }^{\circ} \mathrm{C}$. The insets show a zoomed plot of the adsorption peak at $1500-1000 \mathrm{~cm}^{-1}$, which corresponds to C-O stretching vibrations.

This is in well agreement with the EDX and FTIR results. Meanwhile, Fig. 2 (b) to (d) show the high resolution XPS spectra of Ti 2p, O 1s and $\mathrm{C} 1 \mathrm{~s}$ for $\mathrm{C} / \mathrm{TiO}_{2}-500, \mathrm{C} / \mathrm{TiO}_{2}-700$ and commercial $\mathrm{TiO}_{2}$. In the $\mathrm{Ti}$ 2 p spectra (Fig. 2 (b)), two peaks that appeared at 459 and $465 \mathrm{eV}$ for all of spectra were the typical peaks of Ti $2 \mathrm{p}_{3 / 2}$ and $\mathrm{Ti} 2 \mathrm{p}_{1 / 2}$ binding energy region (Choi et al., 2004, Shao et al., 2010). This indicates the presence of $\mathrm{Ti}^{4+}$ ions in $\mathrm{TiO}_{2}$ (Parayil et al., 2012). The slight shifting in $\mathrm{C} / \mathrm{TiO}_{2}$ peaks from calcination temperature of 500 to $700{ }^{\circ} \mathrm{C}$ was due to the change in the bonding environment of $\mathrm{Ti}$ when calcination temperature increased. For $\mathrm{C} / \mathrm{TiO}_{2}$ calcined at $700{ }^{\circ} \mathrm{C}$ and the commercial $\mathrm{TiO}_{2}$, beside $\mathrm{Ti} 2 \mathrm{p}_{3 / 2}$ binding energy of $\mathrm{Ti}^{4+}$, a new and weak $\mathrm{Ti} 2 \mathrm{p}_{3 / 2}$ core level peak appeared around 456-457.4 eV, suggesting that $\mathrm{Ti}^{3+}$ species were formed in the $\mathrm{TiO}_{2}$ lattice due to the partial reduction of $\mathrm{Ti}^{4+}$ to $\mathrm{Ti}^{3+}$. The emergence of $\mathrm{Ti}^{3+}$ species would result in the formation of oxygen vacancy defects due to $\mathrm{C}$-doping which took place during the synthesis of the catalysts (Raja et al., 2006, Shao et al., 2010).

Fig. 2 (c) displays spectra corresponding to $\mathrm{O} 1 \mathrm{~s}$ region for, $\mathrm{C} / \mathrm{TiO}_{2-}$ 500, $\mathrm{C} / \mathrm{TiO}_{2}-700$ and commercial $\mathrm{TiO}_{2}$. All samples exhibited strong peaks at around $530 \mathrm{eV}$, which is the result of Ti-O bonds and the peak around $532 \mathrm{eV}$ is due to the presence of $\mathrm{C}-\mathrm{O}$ bond. $\mathrm{In} \mathrm{C} / \mathrm{TiO}_{2}-500$ and commercial $\mathrm{TiO}_{2}$, a signal at around $533 \mathrm{eV}$ was detected due to the presence of $\mathrm{C}=\mathrm{O}$ bond. An additional peak at around 527.7-529.1 eV for all the samples is possibly attributed to the presence of $\mathrm{O}$ atoms bonded with $\mathrm{Ti}^{3+}$ (Kumar et al., 2000, Shao et al., 2010). Ti ${ }^{3+}$ ions could act as an electron trap in the photocatalytic reaction and thus preventing the recombination of the charge carriers (Muniandy et al., 2016).

Fig. 2 (d) compares the XPS profiles in the region of $\mathrm{C} 1 \mathrm{~s}$ binding energy for $\mathrm{C} / \mathrm{TiO}_{2}-500, \mathrm{C} / \mathrm{TiO}_{2}-700$ and commercial $\mathrm{TiO}_{2}$. In all of the spectra, the peak attributed to $\mathrm{C} 1 \mathrm{~s}$ was observed in the range of 290 to $282 \mathrm{eV}$ with two to four of deconvulated peaks. The peak signal at around $285 \mathrm{eV}$ for all of the samples corresponds to the $\mathrm{C}-\mathrm{C}$ and $\mathrm{C}-\mathrm{H}$ bonds due to the presence of elemental carbon ( $\mathrm{sp}^{2}$ hybridized carbon) as well as adventitious carbon (Yang et al., 2008, Lim et al., 2010, Shao et al., 2010, Muniandy et al., 2016). The peak around $283 \mathrm{eV}$ corresponded to the $\mathrm{Ti}-\mathrm{C}$ bond due to the substitutional of $\mathrm{C}$ atom to $\mathrm{O}$ in $\mathrm{TiO}_{2}$ lattice (Shao et al., 2010). All spectra have a peak signal around $289 \mathrm{eV}$ that corresponds to the $\mathrm{O}=\mathrm{C}-\mathrm{O}$ bond and an additional peak in $\mathrm{C} / \mathrm{TiO}_{2}-500$ at $287 \mathrm{eV}$, corresponding to $\mathrm{C}-\mathrm{O}$ bond (Muniandy et al., 2016). The presence of the carbonate-like species, $\mathrm{O}=\mathrm{C}-\mathrm{O}$ and $\mathrm{C}-\mathrm{O}$ bond were due to interstitial and/or substitutional $\mathrm{C}$ to $\mathrm{Ti}$ atom in $\mathrm{TiO}_{2}$ lattice (Liu et al., 2014, Muniandy et al., 2016). The presence of these three peaks indicate that $\mathrm{C}$ was self-doped into $\mathrm{TiO}_{2}$ 's lattice at substitutional and interstial positions.

Photoluminescence (PL) study was conducted in order to understand the nature of the electron-hole recombination of the composites. In the field of photocatalysis, it is a good technique to understand the separation efficiency of photogenerated electrons and holes. Fig. 3 illustrates the PL spectra obtained from the recombination of electrons and holes for $\mathrm{C} / \mathrm{TiO}_{2}$ calcined at 300, 400, 500, 600 and $700{ }^{\circ} \mathrm{C}$, and commercial $\mathrm{TiO}_{2}$ in the range of $340-600 \mathrm{~nm}$ with 325 $\mathrm{nm}$ wavelength excitation source. The PL spectra displayed a similar pattern with three main peaks observed at $337-340 \mathrm{~nm}, 362-364 \mathrm{~nm}$ and $408-413 \mathrm{~nm}$. The intense peak observed at $337-340 \mathrm{~nm}$ is assigned to the band luminescence the samples. Peaks at 362-364 nm and 408-413 $\mathrm{nm}$ arise from recombination at dopant levels or sub-band gaps induced by self-doped C and oxygen vacancies (Kavitha and Devi, 2014). Meanwhile, the small emission peak at $468 \mathrm{~nm}$ is due to the surface oxygen vacancies when $\mathrm{Ti}^{3+}$ charge is transferred to oxygen vacancy in $\mathrm{TiO}_{6}{ }^{8-}$ octahedra (Kavitha and Devi, 2014, Kao and Chen, 2017).

The presence of the sub-band gap energy induced by the self-doped $\mathrm{C}$ is further proved by computing the band gap energy of anatase using density functional theory (DFT) as shown in Fig. 4. DFT calculations of 51 atoms $(2 \times 1 \times 1$ supercell $)$ of $\mathrm{Ti}_{21} \mathrm{O}_{30}$ anatase cluster were performed using Gaussian 09 sofware. The C-doped was studied at substitutional position (by replacing oxygen) and interstitial position. The doping concentration of $\mathrm{C}$ at substitutional and interstial position is 1.96 at.\% and 1.92 at.\%, respectively. The calculated results shows that by doping with $\mathrm{C}$, additional energy levels were formed in the band gap of anatase called sub-band gap at $2.13 \mathrm{eV}$ for substitutional and $2.77 \mathrm{eV}$ at interstitial position, which is in the visible light region (Siti Hajar Alias, 2019). 
(a) $\quad 01 \mathrm{~s}$

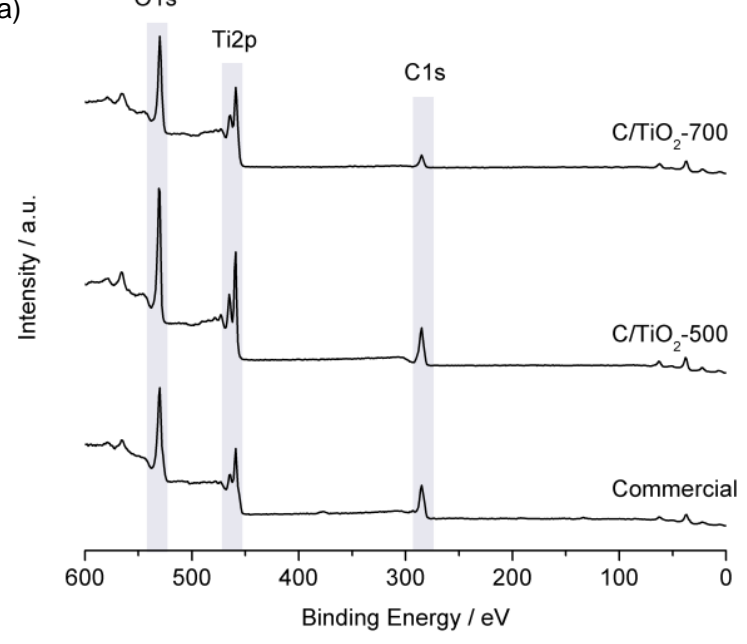

(c)

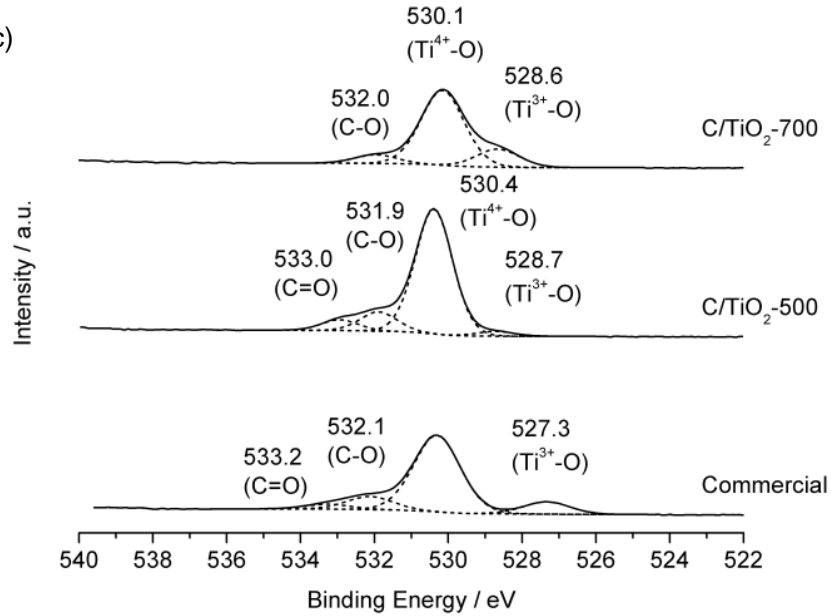

(b)

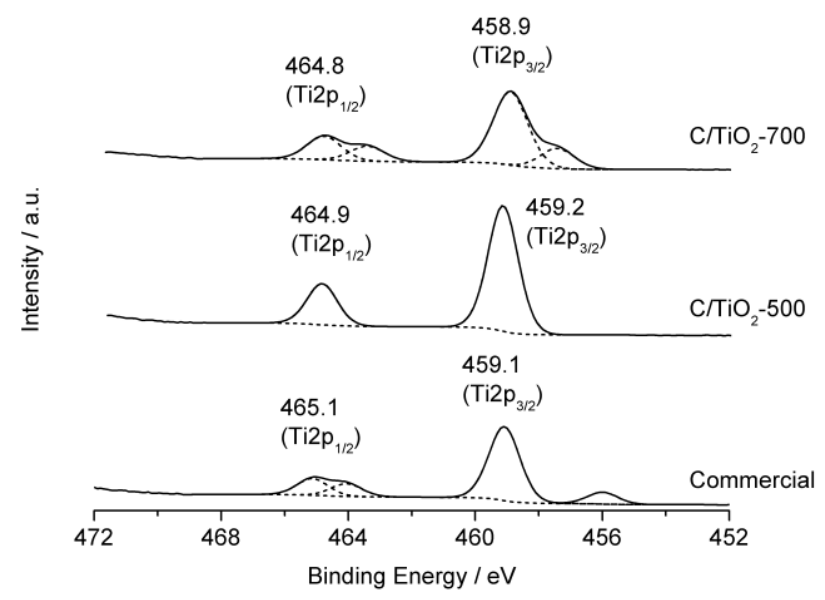

(d)

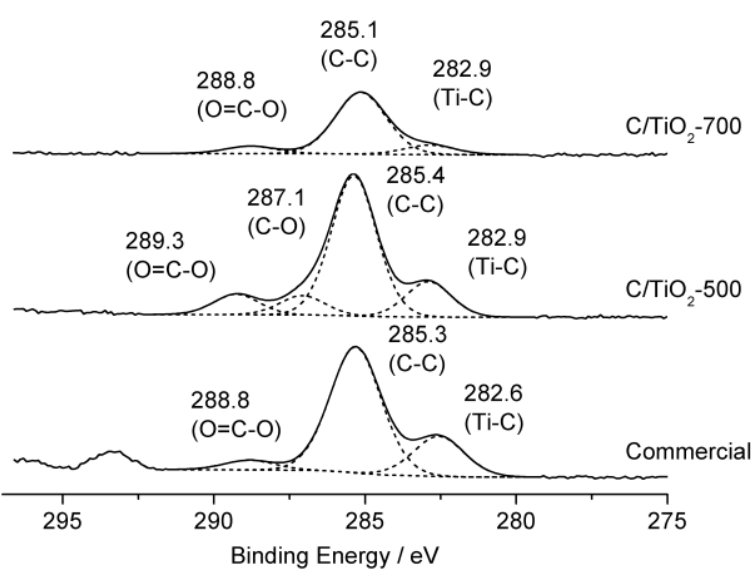

Fig. 2 (a) XPS survey specta and the binding energy of (b) Ti2p, (c) O1s and (d) $\mathrm{C} 1 \mathrm{~s}$ of commercial $\mathrm{TiO}_{2}, \mathrm{C}_{\mathrm{TiO}}-500$, and $\mathrm{C} / \mathrm{TiO}_{2}-700$.

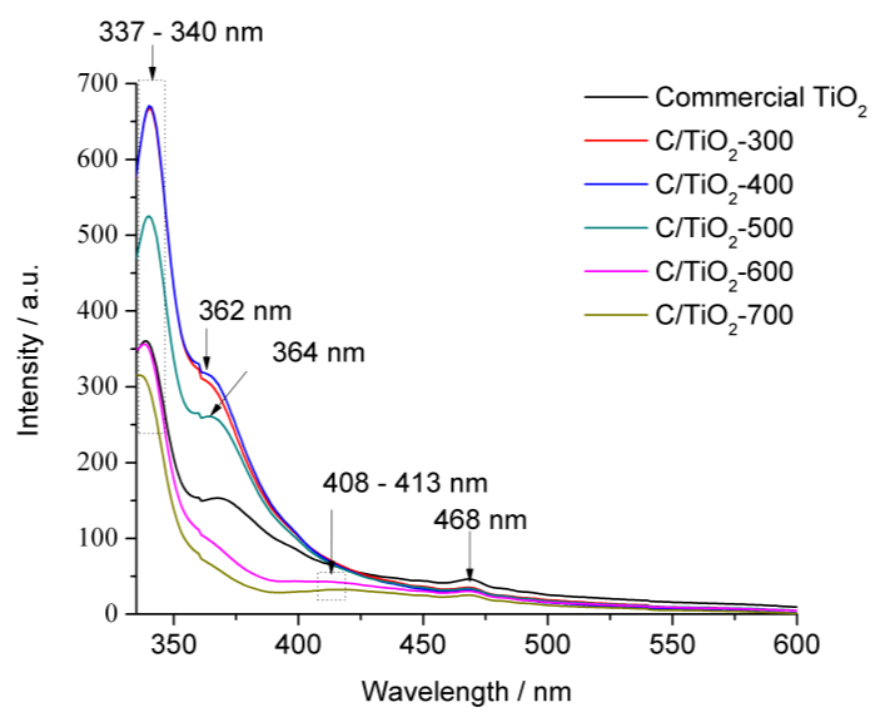

Fig. 3 Photoluminescence spectra of (a) commercial $\mathrm{TiO}_{2}$ and (b) $/ \mathrm{TiO}_{2}$ samples at different calcination temperature (b) 300 , (c) 400, (d) 500, (e) 600 , and (f) $700{ }^{\circ} \mathrm{C}$.

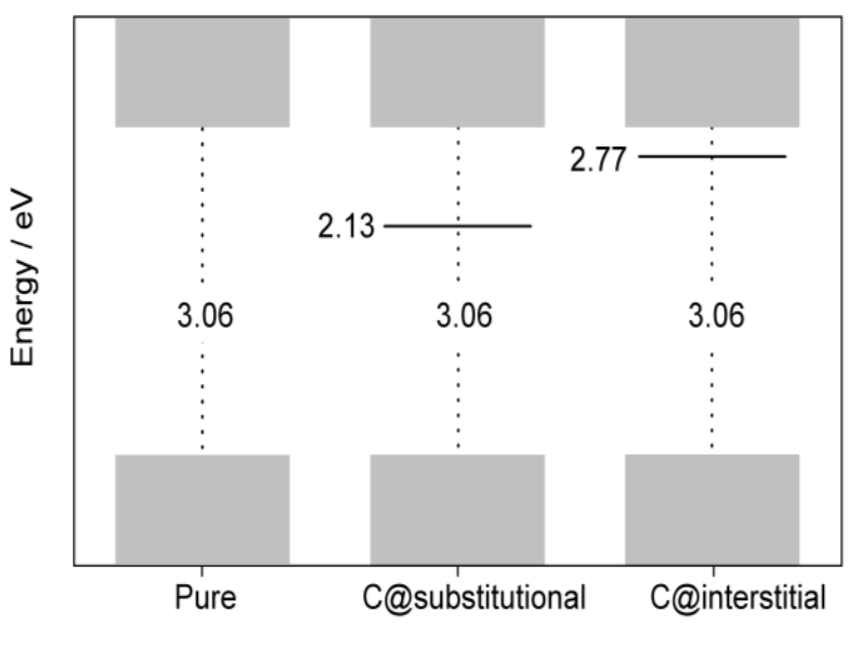

Fig. 4 Schematic illustration of the band gap energy of pure anatase $\mathrm{Ti}_{21} \mathrm{O}_{30}$, C-doped at substitutional position and C-doped at interstial position of anatase $\mathrm{Ti}_{21} \mathrm{O}_{30}$ calculated by DFT. 

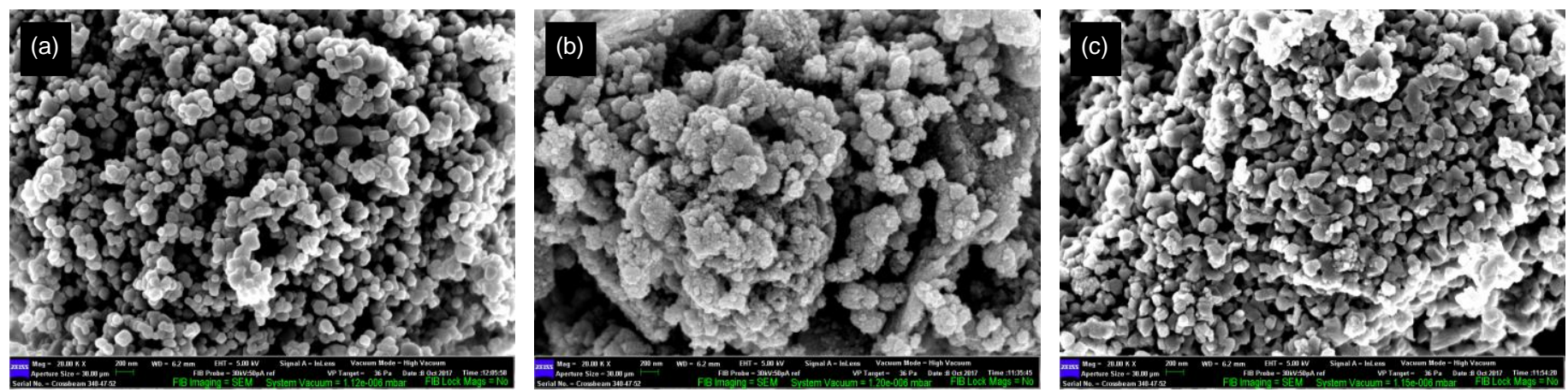

Fig. 6 FESEM images of (a) commercial $\mathrm{TiO}_{2}$, (b) $\mathrm{C} / \mathrm{TiO}_{2}-300$, and (c) $\mathrm{C} / \mathrm{TiO}_{2}-700$ composites.

Fig. 5 (a) shows the XRD pattern of commercial $\mathrm{TiO}_{2}$ anatase. It was observed that the sharp features of the XRD pattern is consistent with the anatase phase. Fig. 5 (b) to (f) shows the effect of calcination temperatures to the phase structures of $\mathrm{C} / \mathrm{TiO}_{2}$. From the results, it can be seen that the calcination temperature strongly influenced the phase composition and crystallinity of the $\mathrm{TiO}_{2}$. As shown in Fig. 5, the $\mathrm{C} / \mathrm{TiO}_{2}$ photocatalyst was in the anatase phase with calcination temperature of 300 to $500{ }^{\circ} \mathrm{C}$ (JCPDS No. 21-1272), with the diffraction peaks observed at $2 \theta$ values of $25.3^{\circ}$ and $48^{\circ}$. As the calcination temperature increased to $600{ }^{\circ} \mathrm{C}$, the phase transformed to rutile phase with the composition of $43.45 \%$. Upon increasing the calcination temperature to $700{ }^{\circ} \mathrm{C}$, the anatase phase was mostly transformed into highly organized rutile phase by reconstruction of the $\mathrm{TiO}_{6}$ octahedral (Hanaor and Sorrell, 2011). The diffraction peaks located at $2 \theta$ values of $27.4^{\circ}, 36.1^{\circ}, 41.2^{\circ}, 54.3^{\circ}$ and $56.6^{\circ}$ were attributed to the rutile phase of $\mathrm{TiO}_{2}$ (JCPDS No. 21-1276). The smallest crystallite sizes are obtained from $\mathrm{C} / \mathrm{TiO}_{2}-300$ and it increased from 5.52 to $28.75 \mathrm{~nm}$, when the calcination temperature increased to $700{ }^{\circ} \mathrm{C}$, as shown in Table 1 . As the calcination temperature increase, the former crystallites also increased, which can be ascribed to the thermally promoted crystalline growth.

The FESEM image of the commercial $\mathrm{TiO}_{2}$ is presented in Fig. 6 (a). It shows that the morphology of the commercial $\mathrm{TiO}_{2}$ is spherical to irregular shapes. Fig. 6 (b) and (c) show the FESEM images of the $\mathrm{C} / \mathrm{TiO}_{2}$ at calcination temperature of 300 and $700{ }^{\circ} \mathrm{C}$, respectively. At $300{ }^{\circ} \mathrm{C}$, FESEM image shows that the $\mathrm{C} / \mathrm{TiO}_{2}$ particles were nonhomogeneous and agglomerated. The formation of spherical $\mathrm{C} / \mathrm{TiO}_{2}$ increased and became more defined as the calcination temperature increased to $700{ }^{\circ} \mathrm{C}$.

The optical response of the $\mathrm{C} / \mathrm{TiO}_{2}$ and its correlation with the increasing calcination temperature was studied by DR UV-Vis spectroscopy. The UV-Vis DR spectra in the axis of Kubelka-Munk of $\mathrm{C} / \mathrm{TiO}_{2}$ photocatalyst calcined at 300 to $700{ }^{\circ} \mathrm{C}$ and for commercial $\mathrm{TiO}_{2}$ are shown in Fig. 7. The figure shows a similar pattern between the $\mathrm{C} / \mathrm{TiO}_{2}$ and commercial $\mathrm{TiO}_{2}$ at about 250 and $320 \mathrm{~nm}$. The absorption in the range of $250 \mathrm{~nm}$ is associated to a charge transfer in tetrahedral-coordinated $\mathrm{Ti}$ between $\mathrm{O}^{2-}$ and the central Ti(IV) atom. The second absorption peak at $320 \mathrm{~nm}$ is assigned to the charge transfer in octahedral-coordinated Ti (Astorino et al., 1995, Zecchina et al., 1996, Nur, 2006). The absorption edges of the $\mathrm{C} / \mathrm{TiO}_{2}$ were remarkably shifted to higher wavelength of $360 \mathrm{~nm}$ when the calcination temperature increased, implying the decrease in the band gap energies from 3.54 to $3.13 \mathrm{eV}$ (refer Table 1).

Fig. 8 shows the nitrogen adsorption-desorption isotherms of $\mathrm{C} / \mathrm{TiO}_{2}$ and commercial $\mathrm{TiO}_{2}$. Commercial $\mathrm{TiO}_{2}$ exhibited the Type III isotherm, characteristics of a non-porous or macroporous solid. As shown in the isotherm, the hysteresis loop in the region of $P / P_{0}$ from 0.8 to 1.0 indicates that a sorption of porous structure and an interparticles porosity among neighbouring particles (Liu et al., 2008). $\mathrm{C} / \mathrm{TiO}_{2}$ calcined at 300 to $600^{\circ}$ showed Type IV isotherm with a $\mathrm{H} 2$ hysteresis loop, characteristics of a mesoporous solid, which differs from that of commercial $\mathrm{TiO}_{2}$. At the highest calcination temperature of $700{ }^{\circ} \mathrm{C}$, the isotherm for $\mathrm{C} / \mathrm{TiO}_{2}$ was identified as Type III isotherm, similar to that of commercial $\mathrm{TiO}_{2}$. The Barret-Joyner-Halenda (BJH) pore size distribution of $\mathrm{C} / \mathrm{TiO}_{2}$ and commercial $\mathrm{TiO}_{2}$ are illustrated in
Fig. 9. The pore size distribution of $\mathrm{C} / \mathrm{TiO}_{2}-700$ and commercial $\mathrm{TiO}_{2}$ confirmed their non-porous structures. The narrow pore size distribution curves imply that $\mathrm{C} / \mathrm{TiO}_{2}$ calcined at 300 to $600{ }^{\circ} \mathrm{C}$ have uniform pores in the mesopore region. The values of BET surface area, pore volume and pore diameter are presented in Table 1 . It is shown that the surface area of $\mathrm{C} / \mathrm{TiO}_{2}$ decreased as the calcination temperature increased, from 150 to $7 \mathrm{~m}^{2} / \mathrm{g}$. On the other hand, when the calcination temperature increased from 300 to $600{ }^{\circ} \mathrm{C}$, the cumulative pore volume and pore diameter of the $\mathrm{C} / \mathrm{TiO}_{2}$ were reduced and enlarged, respectively. The pore volume and pore diameter for $\mathrm{C} / \mathrm{TiO}_{2}$ composite for $700{ }^{\circ} \mathrm{C}$ and commercial $\mathrm{TiO}_{2}$ were not available due to their nonporous structure.

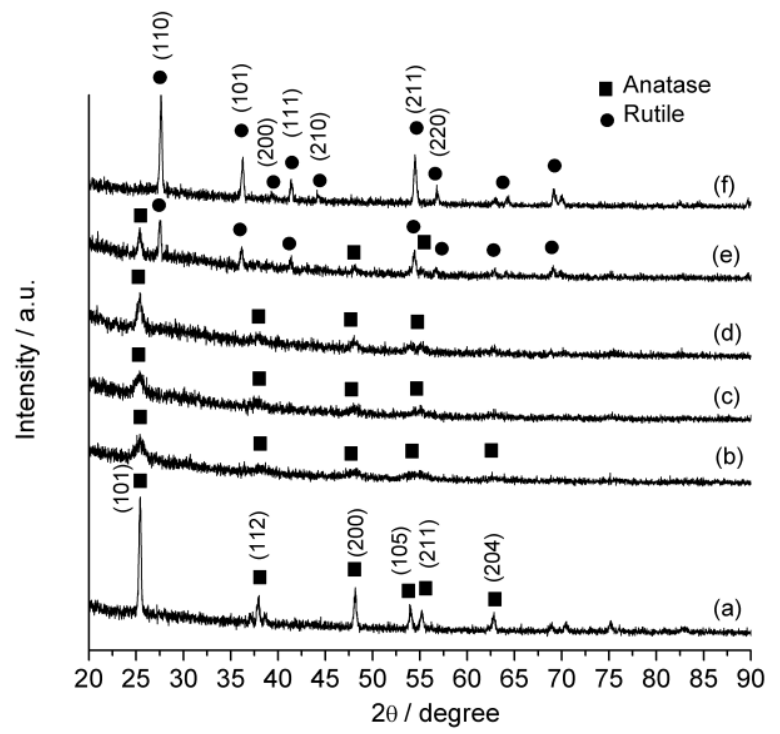

Fig. 5 XRD patterns of (a) commercial $\mathrm{TiO}_{2}$, (b) $\mathrm{C} / \mathrm{TiO}_{2}-300$, (c) $\mathrm{C} / \mathrm{TiO}_{2-}$ 400, (d) $\mathrm{C} / \mathrm{TiO}_{2}-500$, (e) $\mathrm{C} / \mathrm{TiO}_{2}-600$ and (f) $\mathrm{C} / \mathrm{TiO}_{2}-700$

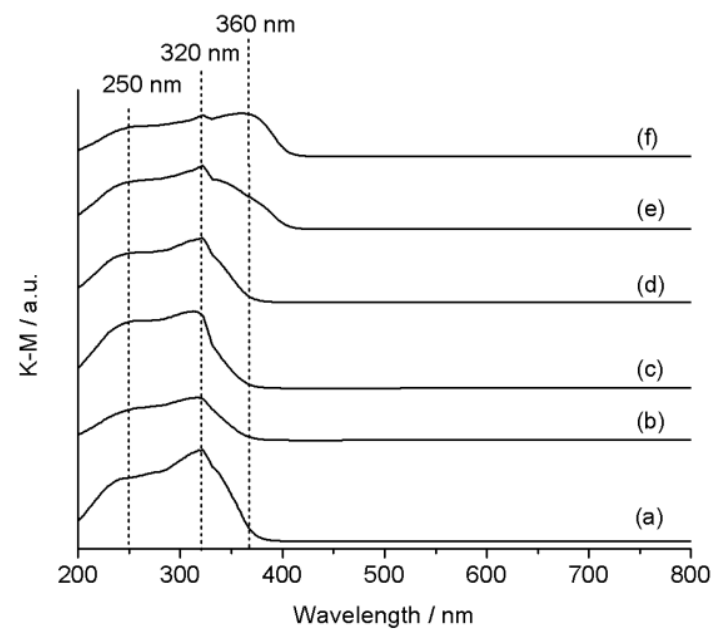

Fig. 7 DR UV-Vis spectra for (a) commercial $\mathrm{TiO}_{2}$, (b) $\mathrm{C} / \mathrm{TiO}_{2}-300$, (b) $\mathrm{C} / \mathrm{TiO}_{2}-400$, (b) $\mathrm{C} / \mathrm{TiO}_{2}-500$, (b) $\mathrm{C} / \mathrm{TiO}_{2}-600$, (b) $\mathrm{C} / \mathrm{TiO}_{2}-700$. 


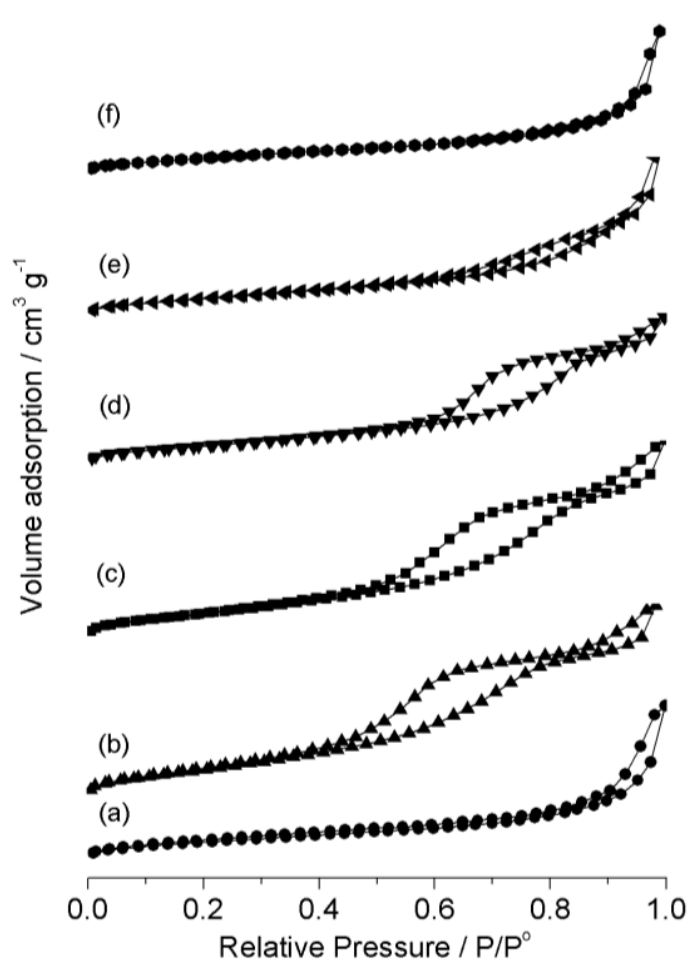

Fig. 8 Nitrogen adsorption-desorption isotherms of (a) commercial $\mathrm{TiO}_{2}$ and $\mathrm{C} / \mathrm{TiO}_{2}$ samples at different calcination temperature (b) 300 , (c) 400 , (d) 500 , (e) 600 , and (f) $700^{\circ} \mathrm{C}$.

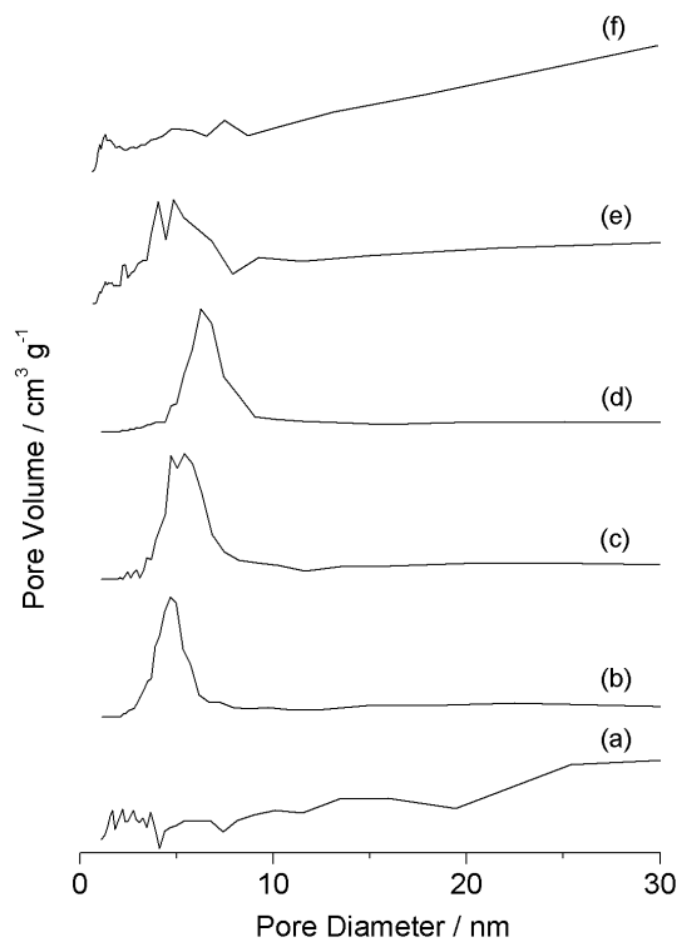

Fig. 9 Pore size distribution curve obtained from the adsorption branch of the isotherm of (a) commercial $\mathrm{TiO}_{2}$ and (b) $\mathrm{C} / \mathrm{TiO}_{2}$ at different calcination temperature (b) 300 , (c) 400 , (d) 500 , (e) 600 , and (f) $700{ }^{\circ} \mathrm{C}$

\section{Evaluation of photocatalytic activity}

The photocatalytic activity of $\mathrm{C} / \mathrm{TiO}_{2}$ composites were tested out in the photocatalytic oxidation of styrene under visible light irradiation. Analysis from gas chromatography indicated that benzaldehyde was the main product, alongside with styrene oxide as the minor product. The trend of photocatalytic activity in the form of yield of products' concentration is displayed in Fig. 8. As comparison, the blank experiment produced very low amount of products, as it is difficult to oxidize styrene in the absence of catalyst. However, the photo- oxidation of styrene by $\mathrm{C} / \mathrm{TiO}_{2}$ photocatalysts and commercial $\mathrm{TiO}_{2}$ were significantly enhanced due to the presence of self-doped $\mathrm{C}$ that has been incorporated in the $\mathrm{TiO}_{2}$ 's lattice which has been proven by the FTIR, XPS and EDX analyses. The Ti-C and $\mathrm{C}-\mathrm{O}$ bonds from the XPS results show the presence of interstitial C-doping as well as $\mathrm{C}$ substitution by replacing oxygen or $\mathrm{Ti}$ atoms in the $\mathrm{TiO}_{2}$ lattice. The self-doped $\mathrm{C}$ induced the sub band in the band gap of $\mathrm{TiO}_{2}$ and hence, significantly enhanced the photocatalytic activity under visible light irradiation. Additionally, PL spectra also shows the presence of defect states. Hence, these characteristics allow $\mathrm{C} / \mathrm{TiO}_{2}$ to be an active photocatalyst under the irradiation of visible light.

The highest total concentration of products (benzaldehyde and styrene oxide) was achieved by the $\mathrm{C} / \mathrm{TiO}_{2}$ photocatalyst calcined at 400 and $300{ }^{\circ} \mathrm{C}$ with the concentration of $1.1 \mathrm{mmol}$ and $1.0 \mathrm{mmol}$, respectively. However, when the calcination temperature of $\mathrm{C} / \mathrm{TiO}_{2}$ further increased to $500-700{ }^{\circ} \mathrm{C}$, the yield of the products decreased. The high yield of products achieved by $\mathrm{C} / \mathrm{TiO}_{2}-300{ }^{\circ} \mathrm{C}$ and $\mathrm{C} / \mathrm{TiO}_{2}-$ $400{ }^{\circ} \mathrm{C}$ could be due to the higher $\mathrm{C}$ content, higher surface area, and the anatase phase crystallinity. The crystal phase and crystallinity are among the most important factors for the photocatalytic activity of $\mathrm{TiO}_{2}$, where anatase phase is considered as the most active form of $\mathrm{TiO}_{2}$, while rutile and amorphous $\mathrm{TiO}_{2}$ are believed to be relatively inactive (Lettmann et al., 2001). Apart from that, it is known that large surface area helps to improve the photocatalytic activity of $\mathrm{TiO}_{2}$. Surface area is correlated to the number of effective active sites, where larger surface area means more active sites, on which target molecules and intermediate products can be adsorbed. To relate the low yield of products by commercial $\mathrm{TiO}_{2}$ to those of synthesized $\mathrm{C} / \mathrm{TiO}_{2}$ photocatalysts is impractical because the synthesis method of the commercial $\mathrm{TiO}_{2}$ is unknown and it might be different from the synthesis steps of $\mathrm{C} / \mathrm{TiO}_{2}$ photocatalyst.

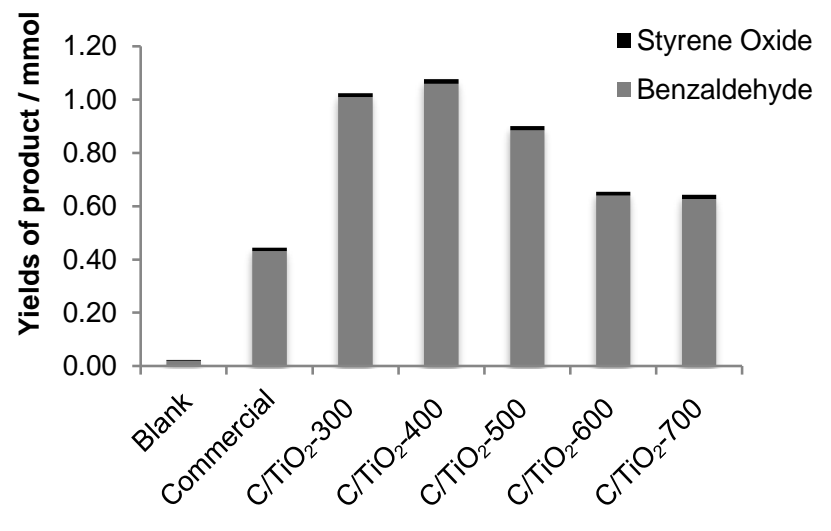

Types of Catalyst

Fig. 8 Amount of products in the photo-oxidation of styrene with hydrogen peroxide under the irradiation of visible light for blank, commercial $\mathrm{TiO}_{2}$ and the prepared $\mathrm{C}$-self doped $\mathrm{TiO}_{2}$ calcined at different temperatures, as the photocatalysts.

\section{CONCLUSION}

In this study, $\mathrm{C}$ self-doped $\mathrm{TiO}_{2}\left(\mathrm{C} / \mathrm{TiO}_{2}\right)$ was synthesized using a simple sol-gel method by using titanium isopropoxide, ethanol and deionized water. Calcination temperatures of the $\mathrm{C} / \mathrm{TiO}_{2}$ photocatalyst affected the crystallinity, phase, morphology, surface area, porosity, crystallite size and amount of carbon present. The $\mathrm{C} / \mathrm{TiO}_{2}$ photocatalyst was found to be effective in oxidizing styrene under visible light irradiation due to the presence of self-doped $\mathrm{C}$ in the $\mathrm{TiO}_{2}$ 's lattice. The self-doped $\mathrm{C}$ induced the sub band gap in the $\mathrm{TiO}_{2}$ and thus enhanced the photo-oxidation under visible light irradiation. $\mathrm{C} / \mathrm{TiO}_{2}-300{ }^{\circ} \mathrm{C}$ and $\mathrm{C} / \mathrm{TiO}_{2}-400{ }^{\circ} \mathrm{C}$ showed high yield of products due to the higher $\mathrm{C}$ content, higher surface area and the anatase phase. Therefore, it is proven that $\mathrm{TiO}_{2}$ synthesized without any external carbon source is also active for visible light photocatalytic reactions due to the presence of self-doped C. 


\section{ACKNOWLEDGEMENT}

This work was financially supported by the Ministry of Science, Technology and Information, Malaysia under Fundamental Research Grant Scheme (R.J130000.7826.4F923) and Universiti Teknologi Malaysia under the Research University Grant and Ministry of Higher Education Malaysia (Vot No. 4L825 and Q.J130000.2526.18H69). One of the authors (Siti Hajar Alias) would also like to thank the Universiti Teknologi MARA Malaysia and Ministry of Higher Education Malaysia for financial support under SLAB/SLAI programme. The authors gratefully acknowlege Prof. Dr. Hadi Nur for the fruitful discussions.

\section{REFERENCES}

Astorino, E., Peri, J. B., Willey, R. J., Busca, G. 1995. Spectroscopic Characterization of silicate-1 and titanium silicate-1. J. Catal., 157, 482500 .

Choi, Y., Umebayashi, T., Yoshikawa, M. 2004. Fabrication and characterization of C-doped anatase $\mathrm{TiO}_{2}$ photocatalysts. J. Mater. Sci., 39, 5, 1837-1839. doi: 10.1023/B:JMSC.0000016198.73153.31.

Ganesan, N. M., Muthukumarasamy, N., Balasundaraprabhu, R., Senthil, T. S. 2015. Importance of carbon (prepared from Azadirachta indica) for photocatalytic applications. Optik (Stuttg). Elsevier GmbH., 126, 22, 3317-3320. doi: 10.1016/j.ijleo.2015.07.129.

Gorska, P., Zaleska, a, Suska, a, Hupka, J. 2009. Photocatalytic Activity and Surface Properties of Carbon-Doped Titanium Dioxide. Physicochem. Probl. Miner. Process., 43, 43, 21-30.

Hamal, D. B., Klabunde, K. J. 2007. Synthesis, characterization, and visible ligh activity of new nanoparticle photocatalysts based on silver, carbon, and sulfur-doped TiO2. J. Colloid Interface Sci., 311, 2, 514-522. doi: 10.1016/j.jcis.2007.03.001

Hanaor, D. a H., Sorrell, C. C. 2011. Review of the anatase to rutile phase transformation. J. Mater. Sci., 46, 4, 855-874. doi: 10.1007/s10853-0105113-0.

Kao, L. H., Chen, Y. P. 2017. Characterization, photoelectrochemical properties, and surface wettabilities of transparent porous $\mathrm{TiO}_{2}$ thin films. $J$. Photochem. Photobiol. A Chem., 340, 109-119. doi: 10.1016/j.jphotochem.2017.03.011.

Kavitha, R., Devi, L. G. 2014. Synergistic effect between carbon dopant in titania lattice and surface carbonaceous species for enhancing the visible light photocatalysis. J. Environ. Chem. Eng. Elsevier Ltd., 2, 2, 857867. doi: 10.1016/j.jece.2014.02.016.

Kumar, M. M., Badrinarayanan, S., Sastry, M. 2000. Nanocrystalline $\mathrm{TiO}_{2}$ studied by optical, FTIR and X-ray photoelectron spectroscopy: Correlation to presence of surface states. Thin Solid Films, 358, 1, 122 130. doi: 10.1016/S0040-6090(99)00722-1.

Lavand, A. B., Malghe, Y. S. 2015. Nano sized C doped $\mathrm{TiO}_{2}$ as a visible light photocatalyst for the degradation of 2,4,6-trichlorophenol. Adv. Mater. Lett., 6, 8, 695-700. doi: 10.5185/amlett.2015.5800.

Lettmann, C., Hildenbrand, K., Kisch, H., Macyk, W., Maier, W. F. 2001. Visible light photodegradation of 4-chlorophenol with a coke-containing titanium dioxide photocatalyst. Appl. Catal. B Environ., 32, 4, 215-227. doi: 10.1016/S0926-3373(01)00141-2.

Lim, G. T., Kim, K. H., Park, J., Ohk, S. H., Kim, J. H., Cho, D. L. 2010 Synthesis of carbon-doped photocatalytic $\mathrm{TiO}_{2}$ nano-powders by AFD process. J. Ind. Eng. Chem. The Korean Society of Industrial and Engineering Chemistry, 16, 5, 723-727. doi: 10.1016/j.jiec.2010.07.012.

Liu, G., Han, C., Pelaez, M., Zhu, D., Liao, S., Likodimos, V., Ioannidis, N., Kontos, A. G., Falaras, P., Dunlop, P. S. M., Byrne, J. A., Dionysiou, D. D. 2012. Synthesis, characterization and photocatalytic evaluation of visible light activated C-doped $\mathrm{TiO}_{2}$ nanoparticles. Nanotechnology, 23, 29, 294003. doi: 10.1088/0957-4484/23/29/294003.

Liu, J., Zhang, Q., Yang, J., Ma, H., Tade, M. O., Wang, S., Liu, J. 2014. Facile synthesis of carbon-doped mesoporous anatase $\mathrm{TiO}_{2}$ for the enhanced visible-light driven photocatalysis. Chem. Commun. Royal Society of Chemistry, 50, 13971-13974. doi: 10.1039/C4CC05544F.

Liu, Y., Zhao, W., Zhang, X. 2008. Soft template synthesis of mesoporous $\mathrm{Co}_{3} \mathrm{O}_{4} / \mathrm{RuO}_{2} \cdot \mathrm{xH}_{2} \mathrm{O}$ composites for electrochemical capacitors. Electrochim. Acta 53, 53, 3296-3304. doi 10.1016/j.electacta.2007.11.022.

Luna, M. D. G. de, Lin, J. C.-T., Gotostos, M. J. N., Lu, M.-C. 2016. Photocatalytic oxidation of acetaminophen using carbon self-doped titanium dioxide. Sustain. Environ. Res. Elsevier Ltd, 26, 4, 161-167. doi: 10.1016/j.serj.2016.02.001.

Muniandy, L., Adam, F., Mohamed, A. R., Ng, E. P., Rahman, N. R. A. 2016 Carbon modified anatase $\mathrm{TiO}_{2}$ for the rapid photo degradation of methylene blue: A comparative study. Surfaces and Interfaces Elsevier
B.V., 5, 19-29. doi: 10.1016/j.surfin.2016.08.006.

Nur, H. 2006. Modification of titanium surface species of titania by attachment of silica nanoparticles. Mater. Sci. Eng. B, 133, 49-54. doi: 10.1016/j.mseb.2006.05.003.

Parayil, S. K., Kibombo, H. S., Wu, C.-M., Peng, R., Baltrusaitis, J., Koodali, R. T. 2012. Enhanced photocatalytic water splitting activity of carbonmodified $\mathrm{TiO} 2$ composite materials synthesized by a green synthetic approach. Int. J. Hydrogen Energy Elsevier Ltd, 37, 10, 8257-8267. doi: 10.1016/j.ijhydene.2012.02.067.

Park, J.-W., Kim, D.-W., Seon, H.-S., Kim, K.-S., Park, D.-W. 2010. Synthesis of carbon-doped $\mathrm{TiO}_{2}$ nanoparticles using $\mathrm{CO}_{2}$ decomposition by thermal plasma. Thin Solid Films Elsevier B.V., 518, 15, 4113-4116. doi: 10.1016/j.tsf.2009.11.013.

Park, Y., Kim, W., Park, H., Tachikawa, T., Majima, T., Choi, W. 2009. Carbondoped $\mathrm{TiO}_{2}$ photocatalyst synthesized without using an external carbon precursor and the visible light activity. Appl. Catal. B Environ., 91, 355361. doi: 10.1016/j.apcatb.2009.06.001

Raja, K. S., Misra, M., Mahajan, V. K., Gandhi, T., Pillai, P., Mohapatra, S. K. 2006. Photo-electrochemical hydrogen generation using band-gap modified nanotubular titanium oxide in solar light. J. Power Sources, 161, 2, 1450-1457. doi: 10.1016/j.jpowsour.2006.06.044.

Shao, G. S., Liu, L., Ma, T. Y., Wang, F. Y., Ren, T. Z., Yuan, Z. Y. 2010. Synthesis and characterization of carbon-modified titania photocatalysts with a hierarchical meso-/macroporous structure. Chem. Eng. J. Elsevier B.V., 160, 1, 370-377. doi: 10.1016/j.cej.2010.03.011.

Simonsen, M. E., Søgaard, E. G. 2010. Sol-gel reactions of titanium alkoxides and water: influence of $\mathrm{pH}$ and alkoxy group on cluster formation and properties of the resulting products. J. Sol-Gel Sci. Technol., 53, 485497. doi: 10.1007/s10971-009-2121-0.

Siti Hajar Alias 2019. Structure-photocatalytic activity relationship of carbon doped titanium dioxide analyzed by density functional theory and fuzzy logic graph. Unpublished Doctoral Thesis. Universiti Teknlogi Malaysia, Johor, Malaysia.

Yang, X., Cao, C., Erickson, L., Hohn, K., Maghirang, R., Klabunde, K. 2008. Synthesis of visible-light-active $\mathrm{TiO}_{2}$-based photocatalysts by carbon and nitrogen doping. J. Catal. Elsevier Inc., 260, 1, 128-133. doi: 10.1016/j.jcat.2008.09.016.

Zecchina, A., Bordiga, S., Lamberti, C., Ricchiardi, G., Lamberti, C., Ricchiardi, G., Scarano, D., Petrini, G., Leofanti, G., Mantegazza, M. 1996. Structural characterization of $\mathrm{Ti}$ centres in Ti-silicalite and reaction mechanisms in cyclohexanone ammoximation. Catal. Today, 32, 97106. 